\title{
Garimpando obras: estado do conhecimento sobre formação permanente de professores, educação especial e docência inclusiva
}

\author{
Sinking works: state of knowledge on permanent teacher training, special education and incluive \\ teaching
}

obras hundidas: estado del conocimiento en formación docente permanente, educación especial y docencia inclusiva

Recebido: 10/02/2021 | Revisado: 14/02/2021 | Aceito: 15/02/2021 | Publicado: 22/02/2021

Luciana Carrion Carvalho
ORCID: https://orcid.org/0000-0002-2659-4359
Instituto Federal de Educação, Ciência e Tecnologia Catarinense, Brasil
E-mail: lucarrioncarvalho@ gmail.com
Helenise Sangoi Antunes
ORCID: https://orcid.org/0000-0001-6503-658X
Universidade Federal de Santa Maria, Brasil
E-mail: professora.helenise@ gmail.com

\section{Resumo}

O estudo consiste no estado do conhecimento desenvolvido na tese de doutorado do programa de Pós-Graduação da Universidade Federal de Santa Maria (UFSM/RS), a partir dos descritores: "Formação Permanente de Professores", "Educação Especial" e "Docência Inclusiva". A escolha desses descritores deu-se por serem constituintes no título da pesquisa "Formação Permanente em Educação Especial: aproximações e afastamentos da docência Inclusiva". A metodologia utilizada foi a pesquisa bibliográfica, de abordagem qualitativa, na busca do que já foi produzido em relação às questões de pesquisa. Nesse sentido, oportuniza a contextualização do objeto de estudo situado no contexto histórico, social e no campo científico. Os artigos encontrados fazem importantes provocações para a área da Educação Especial enquanto campo de saber, nas mais diversas dimensões, como: a "polivalência" por meio das formações, tanto na inicial quanto na continuada; o esvaziamento pedagógico/epistemológico por meio da formação aligeirada para o AEE; a formação de professores nos fundamentos teóricos à problematização da práxis; a Educação Especial como campo de saber ser tratada superficialmente, sendo colocada apenas no imperativo da perspectiva da educação inclusiva, ainda, a formação de professores para a inclusão, na busca de metodologias, técnicas e procedimentos para a inclusão. A partir dessa "garimpada" dos descritores nos repositórios citados, nas pesquisas referendadas neste estado do conhecimento e nas Revistas de Educação Especial da UFSM, foi possível constatar lacunas importantes a serem pesquisadas devido à pouca e/ou inexistência de publicações científicas no contexto de formação permanente de professores para a docência inclusiva, conforme proposta na investigação.

Palavras-chave: Formação permanente de professores; Educação especial; Docência inclusiva.

\begin{abstract}
The study consists of the state of knowledge developed in the doctoral thesis of the Graduate Program of the Federal University of Santa Maria (UFSM/RS), based on the descriptors: "Permanent Teacher Education", "Special Education" and "Inclusive Teaching". These descriptors were chosen because they are constituents in the research title "Permanent Education in Special Education: approaches and departures from Inclusive teaching". The methodology used was bibliographic research, with a qualitative approach, in search of what has already been produced in relation to research questions. In this sense, it provides the contextualization of the object of study located in the historical, social and scientific context. The articles found make important provocations for the area of, Special Education as a field of knowledge, in the most diverse dimensions, such as: "polyvalence" through training, both in the initial and in the continuing; the pedagogical / epistemological emptying through lightened training for the SES; Teacher Training in the theoretical foundations for problematizing praxis; Special Education as a field of knowing how to be treated superficially, being placed only in the imperative of the perspective of inclusive education, still, the Training of Teachers for inclusion, in the search for methodologies, techniques and procedures for inclusion. From this "panning" of the descriptors in the aforementioned repositories, in the research endorsed in this state of knowledge and in the Special Education Journals of UFSM, it was possible to find important gaps to be researched due to the little and / or lack of scientific publications in the context of permanent teacher training for inclusive teaching, as proposed in the investigation.
\end{abstract}

Keywords: Permanent teacher training; Special education; Inclusive teaching. 


\begin{abstract}
Resumen
El estudio consta del estado de conocimiento desarrollado en la tesis doctoral del Programa de Posgrado de la Universidad Federal de Santa María (UFSM/RS), con base en los descriptores: "Formación Docente Permanente", "Educación Especial" y "Docencia Inclusiva". Estos descriptores fueron elegidos porque son componentes del título de investigación "Educación Permanente en Educación Especial: enfoques y desviaciones de la enseñanza inclusiva". La metodología utilizada fue la investigación bibliográfica, con enfoque cualitativo, en busca de lo ya producido en relación a cuestiones de investigación. En este sentido, proporciona la contextualización del objeto de estudio ubicado en el contexto histórico, social y científico. Los artículos encontrados suponen importantes provocaciones para el área de la Educación Especial como campo de conocimiento, en las más diversas dimensiones, tales como: "polivalencia" a través de la formación, tanto en la inicial como en la continua; el vaciamiento pedagógico / epistemológico a través de una formación liviana para la SES; Formación del profesorado en los fundamentos teóricos para problematizar la praxis; La Educación Especial como campo del saber ser tratado superficialmente, ubicándose solo en el imperativo de la perspectiva de la educación inclusiva, aún, la Formación de Docentes para la inclusión, en la búsqueda de metodologías, técnicas y procedimientos de inclusión. A partir de este "panning" de los descriptores en los repositorios antes mencionados, en la investigación avalada en este estado de conocimiento y en las Revistas de Educación Especial de la UFSM, se pudo encontrar importantes lagunas a investigar debido a la escasa y / o carencia de publicaciones científicas en el contexto de la formación permanente del profesorado para la docencia inclusiva, tal como se propone en la investigación.
\end{abstract}

Palabras clave: Formación docente permanente; Educación especial; Enseñanza inclusiva.

\title{
1. Introdução
}

O que dá grandeza às universidades não é o que se faz dentro delas. É o que se faz com o que elas produzem

(Florestan Fernandes, 1966, p. 205).

O estudo a seguir consiste no estado do conhecimento ${ }^{1}$, desenvolvido na tese de doutorado, do programa de PósGraduação da Universidade Federal de Santa Maria/RS (UFSM/RS). Neste sentido, o título "garimpando obras" nomeamos devido ao sentimento emergido durante a longa busca das pesquisas já produzidas nos portais oficiais de repositórios. O sentimento/sensação despertado nesse início de busca nos reportou ao garimpo, este por ser um espaço onde pessoas estão determinadas a encontrar os tesouros produzidos pela natureza, enquanto o tesouro produzido aguarda "ansiosamente" a sua descoberta.

Nesta consciência e respeito ao que foi produzido até aqui, iniciamos o estado do conhecimento a partir dos descritores: "Formação Permanente de Professores", "Educação Especial" e "Docência Inclusiva". A escolha desses descritores deu-se por serem constituintes no título da pesquisa "Formação Permanente em Educação Especial: aproximações e afastamentos da docência Inclusiva" e por estarem em acordo com os objetivos da mesma.

\section{Metodologia}

A abordagem metodológica deste estudo é configurada como pesquisa qualitativa de caráter bibliográfica. A natureza bibliográfica deste estudo se justifica pela sua fundamentação teórica com base nas pesquisas em revistas e trabalhos científicos publicados. Nesse sentido, Gil (2002) nos afirma que "a pesquisa bibliográfica é desenvolvida com base em material já elaborado, constituído principalmente de livros e artigos científicos” (p. 44).

\footnotetext{
1"Construindo o estado de conhecimento de sua tese ou dissertação". De acordo com sua súmula, o seminário metodológico-instrumental busca propiciar ao discente a identificação, a análise e a produção de texto fundamentador de sua monografia de pós-graduação, com base na produção científica sobre educação, fundamentalmente no Brasil, após a promulgação da Lei de Diretrizes e Bases da Educação Nacional de 1996. A consulta bibliográfica se apoia, principalmente, em fontes nacionais, podendo se estender a obras latino-americanas e internacionais. Paralelamente, propõe a reflexão sobre a construção da produção científica como forma textual. Entre seus objetivos, destacam-se: conhecer, sistematizar e avaliar a produção científica da área da Educação na contemporaneidade; elaborar produção textual, apoiada em princípios de estado de conhecimento sobre a temática da tese ou dissertação; subsidiar a construção da dissertação e/ou tese em educação; cultivar habitus científico, visando à prática de pesquisa articulada à realidade; e compreender a produção científica na perspectiva do seu campo (MOROSINI, 2015, p. 111).
} 
O estudo consisti na construção da problemática inserida no campo da educação, na busca do que já foi e/ou está sendo produzido em relação às questões de pesquisa a partir das consultas bibliográficas, o que oportuniza a contextualização do objeto de estudo situado no contexto histórico, social e no campo científico.

No entendimento, estado de conhecimento é identificação, registro, categorização que levem à reflexão e síntese sobre a produção científica de uma determinada área, em um determinado espaço de tempo, congregando periódicos, teses, dissertações e livros sobre uma temática específica. Uma característica a destacar é sua contribuição para a presença do novo na monografia (Morosini \& Fernandes, 2014, p. 155).

Compartilhamos o estado do conhecimento pesquisado nas plataformas da Anped Sul (anos 2014 e 2016), IBCT, Biblioteca Digital de Dissertações e Teses da UFSM/SM e no repertório da Revista de Educação Especial da UFSM.

Para a feitura da pesquisa, sentimos a necessidade de visualizar seguidamente as palavras-chave, a questão de pesquisa, o objetivo geral e os objetivos específicos, para, assim, evitar o risco de desviar o foco da mesma. Percebemos que, com a leitura de muitos títulos e resumos, fica a necessidade de elencar os descritores iniciais. Desta forma, os descritores foram 3 (três): "Formação Permanente de Professores", "Educação Especial" e "Docência Inclusiva". Na medida em que foram se delineando as buscas, foi necessário flexibilizar dois descritores: "Formação Permanente de Professores" para "Formação de Professores", da mesma forma, "Educação Especial" para "Educação Inclusiva", a fim de ampliar as buscas, evitando a limitação de termos, consequentemente, a fragilidade nos resultados.

\section{Resultados e Discussão}

Para cada plataforma existem formas específicas de busca dos descritores, então, relatamos como se deu em cada uma delas. Iniciamos a busca pelo site da Anped Sul, no ano de 2014, em "todos os trabalhos publicados", os resultados encontrados foram:

Quadro 1 - Sistematização dos registros - Anped Sul 2014.

\begin{tabular}{|l|l|}
\hline ANPED SUL 2014 & RESULTADOS \\
\hline DESCRITORES & 0 \\
\hline Docência Inclusiva - todos os artigos publicados & 0 \\
\hline Formação Permanente de Professores - todos os artigos & 20 \\
\hline Formação de Professores - Eixo 6 & 12 \\
\hline Educação Especial - Eixo 22 & \\
\hline
\end{tabular}

Fonte: Autores (2018).

No descritor Formação de Professores, eixo 6 (seis), encontramos 20 (vinte) artigos, apenas 1 (um) parecia que se aproximaria, mas a ênfase dada no artigo deu-se nas políticas públicas no período compreendido entre 2008 a 2013: "Políticas de educação inclusiva para a formação de professores: uma revisão sistemática". Autoras: Maria Amelia Ingles, Marisa Schneckenberg e Rayane Regina Scheidt Gasparelo. Dessa forma, não houve aproximações com meus objetivos.

Para o descritor Educação Especial, no eixo 22 (vinte e dois), o artigo: "Professor de Educação Especial nas políticas de perspectiva inclusiva no Brasil: concepções em disputa". Autora: Kamille Vaz, fez a aproximação na questão referente à formação multifuncional relacionada a(o) Educador(a) Especial. Desta forma, continuamos a busca, agora no ano de 2016, inicialmente no eixo 6 (seis) - Formação de Professores, após, pesquisamos no eixo 22 (vinte e dois) - Educação Especial. 
Pesquisamos ainda em todos os artigos os seguintes descritores: Docência inclusiva e formação permanente de professores. Os resultados encontrados foram:

Quadro 2 - Sistematização dos registros - Anped Sul 2016.

\begin{tabular}{|l|l|}
\hline ANPED SUL 2016 & RESULTADOS \\
\hline DESCRITORES & 0 \\
\hline Docência Inclusiva - todos os artigos publicados & 0 \\
\hline Formação Permanente de Professores - todos os artigos & 18 \\
\hline Formação de Professores - Eixo 6 & 8 \\
\hline Educação Especial - Eixo 22 & 8 \\
\hline
\end{tabular}

Fonte: Dados da Pesquisa.

No eixo 6 - Formação de Professores, dos 18 (dezoito) trabalhos encontrados, nenhum se aproximou ao estudo em questão. No eixo 22 - Educação Especial, dos 8 (oito) artigos encontrados, apenas 1 (um) se aproxima, mas somente no tópico em que apresenta a formação de Educação Especial tornada à polivalência e multifuncional. Título do artigo: "A epistemologia na formação do professor de educação especial nos currículos da UFSM: aproximações iniciais". Autoras: Mariana Luzia Corrêa Thesing, Fabiane Adela Tonetto Costas.

Na plataforma IBCT, selecionamos os filtros desejados para melhor refinar a pesquisa:

Quadro 3 - Sistematização dos registros/filtros na plataforma IBCT.

\begin{tabular}{|l|}
\hline Filtros da pesquisa \\
\hline Busca avançada \\
\hline Descritores entre aspas “'” \\
\hline Correspondência de busca: Todos os termos \\
\hline Idioma: português \\
\hline Tipo de documento: dissertação e após tese \\
\hline Ano de defesa: 2013 a 2018 \\
\hline
\end{tabular}

Fonte: Dados da Pesquisa.

Dessa forma, realizamos a busca dos descritores colocando-os entre aspas, por meio da busca avançada. Na correspondência de busca: escolhemos todos os termos, em idioma, selecionamos o português; no tipo de documento destacamos primeiramente, Dissertação e após Tese e em Ano de Defesa, marcamos período de 2013 a 2018.

Iniciamos a busca pelo descritor "Formação Permanente de Professores", no qual encontramos 54 (cinquenta e quatro) registros em dissertações e 24 (vinte e quatro) em teses. Como a busca ficou muito ampla, distante do tema desejado, pois abarcou diversos temas, refinamos mais um pouco, acrescentando o campo: "Docência Inclusiva", que, não possui registros em dissertações e nem em teses.

Em seguida, realizamos diversas combinações que apresentaremos a seguir: 
Quadro 4 - Sistematização dos registros dos descritores: Formação Permanente de Professores, Educação Especial e Ensino Superior.

\begin{tabular}{|l|l|}
\hline “Formação Permanente de Professores”, “Educação Especial” e "Ensino Superior” \\
\hline Dissertações & 9 \\
\hline Teses & 12 \\
\hline Aproximações & 0 \\
\hline
\end{tabular}

Fonte: Dados da Pesquisa.

Nos descritores referendados, dos 9 (nove) registros de dissertações e 12 (doze) de teses, nenhum trabalho aproximouse da temática deste estudo. O que impulsionou novas combinações que compartilharemos a seguir.

Na nova busca, utilizamos dois descritores fixos: o primeiro como "Formação Permanente de Professores" e o segundo como "Docência Inclusiva", no último campo fomos alterando o descritor, respectivamente, por: "Ensino Superior", após para "EBTT" e, por último, Instituto Federal.

Para os descritores "Formação Permanente de Professores", "Docência Inclusiva" e "Instituto Federal", "EBTT" e "Ensino Superior", respectivamente, constatamos a inexistência de um estudo da envergadura desejada nesta tese. Os resultados encontrados em toda a busca registraram zero publicações.

No sentido de buscar aprofundar a pesquisa, realizamos uma variação no primeiro descritor, alterando de "Formação Permanente de Professores" para "Formação de Professores" com os demais descritores já referidos. A seguir, compartilharemos os achados:

Variação do primeiro descritor "Formação Permanente de professores" para "Formação de Professores" para prosseguir a pesquisa:

Quadro 5 - Sistematização dos registros dos descritores: Formação de Professores, Educação Especial e EBTT

\begin{tabular}{|l|l|}
\hline "Formação de Professores", “Educação Especial” e "EBTT” \\
\hline Dissertações & 5 \\
\hline Teses & 2 \\
\hline Aproximações & 0 \\
\hline
\end{tabular}

Fonte: Dados da Pesquisa.

Novamente, apesar da variação no descritor "Formação de Professores", permaneceu zero aproximações. Pois, na variação, utilizamos os 2 (dois) primeiros descritores "Formação de Professores" e "Docência Inclusiva", alternando o último descritor para: "Ensino Superior", "EBTT" e "Instituto Federal", respectivamente. Não encontramos registros com esses descritores.

Já na busca "Formação de Professores", "Educação Especial" e "Instituto Federal", encontramos 54 (cinquenta e quatro) dissertações e 34 (trinta e quatro) teses.

Dessas 54 (cinquenta e quatro) dissertações, apenas 3 (três) referem-se a algum tópico da pesquisa em questão, mas se distanciam em seus objetivos: a primeira tem como foco o trabalho docente na verticalização do IFB, a segunda trata-se do ensino no IF e a terceira da formação docente para a educação profissional e tecnológica no IFMG.

Dentre as 34 (trinta e quatro) teses encontradas, apenas uma poderia aproximar-se nos resultados, no sentido de abordar a necessidade de criar uma cultura de interdisciplinaridade nos cursos de licenciaturas, mas não contempla o objetivo desta tese, pois se afasta nos demais pontos, como: “o presente estudo objetivou investigar os Projetos Pedagógicos de Cursos 
(PPC) e as matrizes curriculares da formação inicial de professores do Instituto Federal de Educação, Ciência e Tecnologia de Goiás (IFG) de modo a analisar e discutir como se constitui a disciplina de Educação Especial nos cursos de licenciaturas estudados. De modo a debruçar na formação inicial de professores do IFG, tem-se como objetivos específicos identificar a presença da disciplina de Educação Especial e suas contribuições para o processo de inclusão educacional; compreender de que forma esta instituição possibilita a inclusão dos(as) alunos(as) em condição de deficiência por meio dos documentos analisados; e, por último, analisar como os PPC dos cursos de licenciatura do IFG se articulam com o processo de inclusão educacional, considerando as matrizes curriculares como "pano de fundo" de tal processo". Título do trabalho "A formação de professores e a (in)visibilidade da educação especial nos projetos pedagógicos dos cursos de licenciatura do Instituto Federal de Goiás", ano de 2017, autor: Souza, Calixto Júnior de.

Ao esgotar as possibilidades e combinações para o primeiro descritor e sua variação, passamos para o segundo descritor: "Educação Especial". Lembrando que os filtros continuaram os mesmos utilizados na busca do primeiro descritor: os descritores entre aspas, o idioma português, período compreendido entre 2013 a 2018, busca realizada primeiramente em dissertações e, após, em teses.

Na combinação inicial realizada entre "Educação Especial" e "Educação Inclusiva", foram encontradas 329 (trezentas e vinte e nove) dissertações e 125 (cento e vinte e cinco) teses. Em uma análise, percebemos a amplitude de títulos e áreas que não convergem a esse estudo. Notamos uma certa fragilidade nas conceituações entre Educação Especial, Educação Inclusiva e AEE, como sinônimos em alguns momentos.

Para refinar a busca, utilizamos um terceiro campo, "Instituto Federal", "EBTT" e "Ensino Superior", respectivamente. Os resultados encontrados foram:

Os descritores "Educação Especial", "Docência Inclusiva" em combinação com os demais descritores: "Instituto Federal", "EBTT” e, por último, "Ensino Superior", apresentaram zero registros de dissertações e teses.

Buscando flexibilizar a pesquisa, a variação do descritor "Educação Especial" para "Educação Inclusiva". Nessa perspectiva, com o novo desenho: "Educação Inclusiva" e "EBTT", encontramos 2 (duas) dissertações que não se aproximam do objeto estudado e nas teses: zero registros. Este resultado nos chamou muita nossa atenção, pois acreditávamos que encontraríamos pesquisas no paradigma de educação inclusiva na EBTT, na construção de uma nova configuração de docência na Educação Especial, uma vez que é discutida de forma ampla a inclusão educacional em todos os níveis educativos.

Nos descritores "Educação Inclusiva" e "Instituto Federal", encontramos 44 (quarenta e quatro) dissertações e 19 (dezenove) teses.

Dessas 44 (quarenta e quatro) dissertações, 5 (cinco) poderiam ter alguma aproximação, mas, ao verificar os resumos dos mesmos, ficou percebido o distanciamento, conforme relataremos: o primeiro trabalho tem por objeto as "Representações Sociais de egressos do curso de Licenciatura em Biologia do Instituto Federal de Educação, Ciência e Tecnologia do Pará. [...] Os resultados mostram que as representações dos professores acerca do objeto de estudo apresentam-se de forma variada, reforçando a imagem do aluno com necessidades educacionais especiais, associada à concepção de deficiência e de aluno que foge ao modelo estabelecido pela sociedade".

A segunda dissertação "investiga como têm sido delineadas as políticas de inclusão no Instituto Federal de Educação, Ciência e Tecnologia do Espírito Santo (IFES)". Em seus resultados de pesquisa, "constata a existência de algumas políticas, ações e movimentos no sentido da inclusão na Instituição, mas também de algumas dificuldades para efetivá-los". "Constata também a necessidade de a Instituição envidar seus esforços na implantação de políticas mais estruturadas pensando na educação para todos".

A terceira dissertação trata da "formação continuada de professores do ensino médio para a educação especial na perspectiva da educação inclusiva” (2017), de autoria de Noronha, Lílian Freire. Esta "pesquisa teve como objetivo analisar a 
formação continuada de professores que atuam no Ensino Médio do IFAM para o processo de ensino do alunado da Educação Especial na Perspectiva da Educação Inclusiva. [...]. Quanto aos professores, o resultado mais expressivo foi o de 92,0\% de respondentes da pesquisa que não realizaram nenhuma formação continuada, relacionada à Educação Especial, nos últimos três anos. Positivamente, 53,1\% dos participantes da pesquisa já leram ou ouviram falar a respeito da Política Nacional de Educação Especial na perspectiva da Educação Inclusiva contra o percentual de 34,7\% que não ouviu falar na mesma. Relacionado ao NAPNE, 72,0\% conhecem esse núcleo, mas apenas 4,0\% já realizaram algum curso nele. Quanto às contribuições, a pesquisa auxiliou para o esclarecimento acerca de como está ocorrendo a formação continuada de professores que atuam junto aos alunos da Educação Especial. Assim como colocar em discussão essa temática no ambiente acadêmico para tentar propiciar reflexões que venham a materializar ações concretas para a qualidade do ensino dos alunos".

A quarta dissertação refere-se: "O fazer pedagógico do professor de Educação Especial/AEE no Instituto Federal Farroupilha: desafios da inclusão" (2017), de autoria de Medeiros, Bruna de Assunção. A pesquisa "buscou analisar como se constitui o fazer pedagógico dos Professores de Educação Especial/AEE no Instituto Federal de Educação, Ciência e Tecnologia Farroupilha - IFFar. Além disso, procurou entender como o Atendimento Educacional Especializado - AEE vem se efetivando, tendo em vista que, atualmente, os Institutos Federais, assim como as Escolas de Ensino Básico e as Universidades, também passaram a se ocupar dos processos de inclusão, implementando o AEE. Aponta que, apesar de toda essa nova conjuntura política, educacional e conceitual que tem permeado sua prática e sua identidade institucionalmente, percebem-se como professoras de Educação Especial atuando no momento como professoras de Educação Básica, Técnica e Tecnológica".

Lemos na íntegra a dissertação, um estudo de significativa envergadura para a área de Educação Especial, onde “denuncia”, questiona, convida à reflexão sobre os desdobramentos ocorridos na Educação Especial em relação à Política Nacional de Educação Especial na Perspectiva da educação inclusiva instituída nacionalmente em 2008. Algumas questões de discussões se aproximam, mas no objetivo da tese há o distanciamento, pois a tese tem como objetivo à construção de uma nova configuração de docência da Educação Especial como foco, pois replicar a atuação nesse "entre lugar" de acordo com a política de 2008 perde o sentido da especificidade da área, o que tem exigido o retorno às discussões sobre nosso saber/fazer. Nesse sentido, destacamos na construção de docência inclusiva como propositura de trabalho docente inclusivo na EBTT para além do AEE.

O quinto trabalho refere-se ao "trabalho docente articulado: a relação entre a educação especial e o ensino médio e tecnológico" (2013), de autoria de Honnef, Claucia. Esse estudo apresenta "a proposição do trabalho docente articulado entre professores de educação especial e de classe comum nas classes regulares, a partir da inserção de alunos com necessidades educacionais especiais (NEE) nesses espaços. O trabalho docente articulado é proposto como uma adaptação ao ensino colaborativo, que prevê o trabalho conjunto dos professores citados no planejamento da aula, no desenvolvimento desta e na avaliação das atividades de sala de aula. O objetivo deste estudo foi verificar e analisar quais os limites e possibilidades da Educação Especial articulada ao Ensino Médio e Tecnológico. Todos os professores mencionaram perceber o trabalho docente articulado como importante, porém, poucos citaram fatores que dificultam sua realização, como por exemplo, o baixo número de professores de educação especial e de classe comum, e o pouco tempo para realização deste trabalho. Deste modo, o que se percebe hoje no contexto educacional é a massificação da ideia de inclusão educacional escolar, sem haver investimentos que garantam condições para que se possa proporcionar ensino-aprendizagem aos estudantes".

No repositório de teses, apenas uma poderia aproximar-se do estudo que se propôs em realizar na tese de doutoramento, intitulada "Transversalidade, inclusão e práticas pedagógicas: possibilidades para operacionalizar políticas e repensar currículos" (2016), de autoria de Pereira, Andreia Cabral Colares. "Esta pesquisa buscou compreender como o corpo docente do Instituto Federal de Educação, Ciência e Tecnologia Sul-Rio-Grandense - IFSul vem atendendo à significativa demanda de estudantes com deficiência e como os docentes transpuseram suas lacunas de formação específica em seus 
currículos ao criarem práticas pedagógicas, estratégias e recursos para proporcionar aos discentes oportunidades de aprendizagem, organização de suas estratégias/práticas pedagógicas, desafios e oportunidades vivenciadas no seu cotidiano docente, apesar das múltiplas limitações identificadas, tanto em nível de políticas, infraestrutura ou ecossistema escolar. Os resultados apontam a fragilidade na formação dos professores para tratar a questão da educação inclusiva na perspectiva da transversalidade. No que se refere a processos educacionais, ao conhecimento de práticas pedagógicas inclusivas; estamos carentes de profundas reflexões e isso se percebe nos currículos de formação de professores, que, quando tratam da questão da inclusão, abordam-na de forma fragmentada".

Ao término da investigação referente ao segundo descritor e sua variação, passaremos para o terceiro descritor "Docência Inclusiva". Encontramos somente dois registros em dissertações, sendo que nenhuma se aproxima do trabalho proposto e nenhum registro em teses. O que nos fez perceber da relevância desta pesquisa de tese.

Finalizadas as buscas no repertório do IBCT/BDTD, direcionamos nossa procura ao Manancial Repositório Digital da UFSM. Terceiro repositório.

Iniciamos a busca com o descritor "Docência Inclusiva" e tivemos como resultados em dissertação 0 (zero) registros e 1 (um) registro de tese, sendo que essa não se aproxima dos objetivos desta pesquisa.

Segunda busca: "Formação permanente de Professores" e "Educação Especial": 12 (dose) dissertações 3 (três) teses, sendo que nenhum tem proximidade com o estudo em questão.

Terceira busca: "Formação permanente de professores" e "educação inclusiva": encontramos 3 (três) dissertações, nenhuma se aproxima e 49 (quarenta e nove) teses, sendo que uma poderia ter proximidade se, caso, o viés fosse na formação de professores de Educação Especial.

A quarta busca se deu nos descritores: "Docência inclusiva", "Formação permanente de professores" e "EBTT"; teve 0 (zero) registros de dissertações e 0 (zero) registros de teses.

Por último, realizamos a busca com os descritores "docência inclusiva", "formação de professores" e "EBTT". Desse modo encontrei 2 (duas) dissertações, destas nenhuma se aproxima, sendo que uma já foi mencionada, defendida em 2017, por Bruna de Assunção Medeiros, comentada anteriormente.

Considerando os achados e os não-achados por meio do estado do conhecimento, o descritor inicial "formação permanente de professores" e sua variação, "formação de professores", com as combinações "Educação Especial", com a variação "educação inclusiva" e "docência inclusiva", nas instituições: "Instituto Federal", "Ensino Superior" e "EBTT", as pesquisas voltam-se para os PPC e as matrizes curriculares da formação inicial dos professores, especificamente buscando identificar a presença da disciplina de Educação Especial e suas contribuições para o processo de inclusão dos alunos em condição de deficiência, disciplinas voltadas à Educação Especial e, principalmente, à Libras. Também a pesquisa referente a currículos, práticas pedagógicas, políticas públicas, inclusão dos alunos com deficiência, estes temas relacionados a todos os níveis de ensino, da Educação Infantil ao Ensino Superior.

Pesquisamos também nos periódicos da Revista de Educação Especial/UFSM, no período de 2013 a 2018, onde encontramos 5 (cinco) artigos com possibilidades de aproximação com a tese. A busca deu-se pelo título e leitura do resumo, que referenciassem: Formação de Professores/Formação Continuada/Formação Permanente, com Educação Especial/Educação Inclusiva/AEE, ainda, Docência/Docência Inclusiva. Após a seleção, fizemos a leitura na íntegra dos artigos selecionados. Em seguida, apresentaremos os artigos numerados do ano de publicação, do mais antigo (2014) ao mais atual (2017), em consonância com os critérios acima expostos, com os respectivos resumos e um breve comentário. São eles: 
1. Alguns efeitos do nosso tempo na formação de Professores da Educação Especial. Prof ${ }^{a} \operatorname{Dr}^{a}$ Leandra Boêr Possa e $\operatorname{Prof}^{a} \operatorname{Dr}^{a}$ Maria Inês Naujorks;

Resumo: "A vontade de saber e problematizar aquilo que parece tranquilo e naturalizado em torno da formação do professor/a da Educação Especial é os efeitos de uma estratégia política neoliberal que opera nos processos de objetivação/sujeição de um sujeito que se produz profissional da Educação Especial. A trama que legitima processos de formação, como um eterno momento de aprendizagem para a profissão, é um modo de subjetivação no qual, todos são capturados a exercermos sobre nós mesmos um tipo de poder que se dobra a partir das relações que exercemos sobre nós mesmos e sobre os outros. Este texto problematiza as discussões em torno da formação de professores da Educação Especial a partir de três temas, são eles: a Inclusão, a Escola inclusiva e a Educação para todos; o binômio da Educação Especial que apresenta o campo clínico em contrário ao da Educação; e, a perspectiva totalizante e polivalente que vem contornando o discurso da política de formação do professor/a da Educação Especial. Para concluir, apontamos a necessidade de desnaturalizar um modelo dado à formação de professores/a da Educação Especial, para que possamos perceber contingencialmente os regimes de verdade e a racionalidade política que organizam e estruturam tal formação. Propomo-nos a pensar sobre os efeitos que estes regimes de verdade, já que não temos como escapar deles, produzem no modo como se subjetivam aqueles, que pela formação, constituem-se professores de tal campo".

Após a leitura do resumo, partimos para a leitura do artigo completo, o qual refere-se, entre outros pontos, à "denúncia” à subjetivação/objetivação do sujeito por meio do discurso neoliberal nas formações iniciais e continuadas de professores da Educação Especial. A polivalência como estratégia que opera nos processos de subjetivação/objetivação de um sujeito que se produz profissional da Educação Especial como um eterno momento da aprendizagem para a profissão.

2. Formação do professor do atendimento educacional especializado: a Educação Especial em questão. $\operatorname{Prof}^{a} \operatorname{Dr}^{a}$ Elisabeth Rossetto ${ }^{3}$.

Resumo: "O presente artigo tem como objetivo discutir a formação e as atribuições do professor do Atendimento Educacional Especializado (AEE) realizado na sala de recursos multifuncional (SRM). O estudo em questão é de caráter documental e bibliográfico. Na investigação documental selecionamos normativas legais que se referem especificamente ao AEE, considerando-se que este se constitui no espaço prioritário para o atendimento aos alunos com deficiência inseridos no ensino regular. A parte bibliográfica deu-se sob o enfoque da Teoria Histórico-Cultural, por ser o referencial teórico que tem contribuído significativamente ao se tratar do processo de escolarização da pessoa com deficiência. Nossa investigação levounos a perceber que a preparação direcionada ao professor encontra-se imbuída de características que denotam superficialidade teórica, com grande adesão à modalidade de ensino a distância, com ênfase em procedimentos técnicos e na disponibilização do uso de recursos. Entendemos que tal formação não contribui para o processo de apropriação de conhecimentos por parte dos alunos e compromete os conteúdos escolares e o ato de ensinar. Nesse sentido reconhecemos a relevância de investimentos em uma qualificação mais consistente, que instrumentalize teoricamente o professor. Ademais a partir deste referencial, ressaltamos a importância da ação docente enquanto mediação para o processo de escolarização e humanização dos alunos com deficiência, uma vez que está no conhecimento uma via pela qual o aluno com deficiência compensa suas limitações e é capaz de superar as características causadas pela própria deficiência".

O artigo apresentado pontua, com grande ênfase, o esvaziamento pedagógico/epistemológico na formação aligeirada para o AEE. A preocupação na caracterização de serviços, técnicas e recursos coloca em risco um campo de saber pedagógico,

2 https://periodicos.ufsm.br/index.php/educacaoespecial/article/view/7655

3 https://periodicos.ufsm.br/educacaoespecial/article/view/13367 
a Educação Especial, pelo discurso do fazer em detrimento do saber como substituto. Nesse sentido, ao analisar as atribuições do professor de acordo com os documentos legais, sugere a conceituação de "professor multifuncional", coloca-se uma formação cuja consistência é questionável, onde o AEE é compreendido como um conjunto de serviços, e a atividade docente voltada ao ensino dos conteúdos não é mencionada. Paralelamente a educação especial, como área de pesquisa e campo de conhecimentos, é desvalorizada, pois, ao longo do material, há a defesa de que o AEE é equivalente à Educação Especial. Nesse sentido, existem aproximações em algumas ponderações, mas afastamentos em relação a esta tese.

3. Formação de professores e sua relação com a educação inclusiva: desafios à experiência teórica na práxis pedagógica. Prof ${ }^{a}$ Dr $^{\mathrm{a}}$ Valdelúcia Alves da Costa ${ }^{4}$

Resumo: "Considerando resultados de pesquisa, este texto tem por objetivo problematizar a formação de professores e sua relação com a educação inclusiva, ao mesmo tempo em que analisa os desafios à experiência teórica na práxis pedagógica inclusiva. Tanto a problematização quanto a análise, se voltam a uma questão central: mesmo considerando os avanços contemporâneos nos processos de formação de professores em prol da educação inclusiva, ainda é necessário desenvolver a formação docente em sua dimensão teórica, na superação da pseudo ideia de que a práxis docente e os métodos canônicos de ensino, sejam pensados como um fim em si mesmos, como também suficientes no enfrentamento e superação dos limites sociais, impostos historicamente aos professores como sendo limites humanos. Esta práxis pedagógica banaliza e/ou nega a demanda humana por uma formação teórica, que possibilite tanto o pensar quanto a atuação político-investigativa contrária à segregação de alunos com deficiência na escola pública e nas demais instâncias sociais. Admitir essa perspectiva formativa, pela experiência teórica, contribuirá na humanização dos professores e dos alunos, com e sem deficiência, ao se contrapor à dominação e à inconsciência social, marcas da sociedade de classes, presentes na escola pública".

$\mathrm{O}$ artigo contribui na reflexão sobre a formação de professores na perspectiva inclusiva, com destaque nos fundamentos teóricos que necessariamente, remetem à problematização da práxis. Destaca ainda, sobre a importância dessa formação teórica, como potência à autonomia na sua função política e investigativa em sua concepção pedagógica, também na tomada consciente de decisões tanto na elaboração quanto na execução de seu planejamento. Ainda, problematiza a substituição dos fins pelos meios na educação inclusiva, devido ao aligeiramento e à banalização das possibilidades dos professores experienciarem teoricamente sua formação junto com os alunos considerados deficientes. Nesse sentido, substitui, também, a possibilidade de se viver a experiência teórica no processo de formação humana e docente, obstando a práxis emancipadora. Existe alguma proximidade em alguns pontos de questionamento/sugestão para a formação de professores para a educação inclusiva.

4. A emergência da Educação Especial como campo de saber e suas atualizações para o presente. $\operatorname{Prof}^{a} \operatorname{Dr}^{\mathrm{a}}$ Leandra Bôer Possa ${ }^{5}$.

Resumo: “A centralidade do sujeito como objeto e protagonista da produção dos saberes na modernidade, narra a história e produção de conhecimentos verdadeiros, a descrição de um lugar da normalidade em contraponto com a anormalidade e um ordenando de um campo de saber chamado de Educação Especial. Esta é a tônica deste artigo que pretende olhar para a atualidade dos relatórios em que Jean Itard relata sua atuação e o consequente processo educativo de Victor, o menino selvagem. Sob a perspectiva das noções de ordenamento dos saberes e normalização, retirada dos estudos foucautianos, realiza-se uma analítica dos fragmentos dos relatórios de Jean Itard como acontecimento que possibilitam compreender de que

4 https://periodicos.ufsm.br/index.php/educacaoespecial/article/view/9628

5 https://periodicos.ufsm.br/educacaoespecial/article/view/23647 
forma essas experiências, do início do século XIX, constituem-se contemporâneas para o campo de saber da Educação Especial".

O artigo apresenta de forma sucinta, o surgimento da Educação Especial, trazendo à reflexão atual com a inclusão. Traz ainda a ideia de um rompimento com as práticas da Educação Especial do passado: nos paradigmas segregacionistas, interacionistas e provoca a pensar nas práticas inclusivistas. Dessa forma, aponta a superficialidade de como é tratado o tema caso se considere a Educação Especial como um campo de saber. Assim, para que seja possível romper com os modos de pensar a Educação Especial (do passado), não basta colocarmos nela o imperativo da perspectiva da educação inclusiva.

5. A Formação de professores para inclusão tratada na Revista Brasileira de Educação Especial: uma análise. Prof ${ }^{a}$ MS Jacqueline Lidiane de Souza Prais, Prof. Dr. Vanderley Flor da Rosa ${ }^{6}$.

Resumo: "A formação de professores para atuar juntos aos alunos com necessidades educacionais especiais (NEE) tem sido apontada pela literatura na área de Educação Especial e da Educação como uma necessidade emergente para se efetivar a educação inclusiva. Motivados por esse argumento, este artigo tem o objetivo de caracterizar as publicações referentes ao tema formação de professores para inclusão dos alunos com NEE contidas na Revista Brasileira de Educação Especial no período de 2005 a 2014. Utiliza-se como metodologia de pesquisa a revisão sistemática das edições on-line disponíveis. Os primeiros resultados indicaram 333 artigos publicados contemplando diversos temas na área da Educação Especial, dentre estes 19 foram selecionados para análise do conteúdo, considerando que tinham como tema central a formação de professores. Após a leitura dos artigos e análises, foram organizados em cinco categorias que apresentaram as seguintes discussões: análise da/na formação inicial de professores; a formação de professores como prática colaborativa para inclusão; análise de curso/programa de formação continuada; revisões e análises de produções científicas acerca da formação de professores e; por fim, a necessidade de formação pedagógica para atuação educacional. Dentre os resultados obtidos nesta pesquisa, evidenciou-se que além do tema formação de professores ter assumido papel de relevância nas pesquisas, ocupa pouco espaço como objeto central das pesquisas e, assim, se faz necessário ampliar as análises para contribuir com a divulgação de trabalhos desenvolvidos na formação inicial e continuada, bem como para reformulação/reestruturação de cursos e programas".

Após a leitura cuidadosa do artigo, percebemos que o mesmo traz como apontamentos a busca de metodologias, técnicas e procedimentos para a inclusão. Como indicativo, traz a necessidade de ampliar investigações na formação inicial e continuada, bem como de conduzir reformulações/reestruturações nos cursos e programas de formação de professores.

\section{Considerações Finais}

Os artigos citados fazem importantes provocações para a área da Educação Especial enquanto campo de saber, nas mais diversas dimensões, como: a "polivalência" por meio das formações, tanto na inicial quanto na continuada; o esvaziamento pedagógico/epistemológico por meio da formação aligeirada para o AEE; a Formação de Professores nos fundamentos teóricos à problematização da práxis; a Educação Especial como campo de saber ser tratada superficialmente, sendo colocada apenas no imperativo da perspectiva da educação inclusiva, ainda, a Formação de Professores para a inclusão, na busca de metodologias, técnicas e procedimentos para a inclusão.

Nesse sentido, os artigos encontram algumas aproximações do estudo, mas se afastam do objetivo da pesquisa, que é compreender nesse "entre lugar", a EBTT, a construção de uma nova configuração de docência na Educação Especial. Assim, esta pesquisa concentra-se em compreender a docência em Educação Especial na Educação Técnica, Tecnológica e Superior, com vistas à construção de uma docência para além do AEE, em busca de formação permanente para uma docência inclusiva.

6 https://periodicos.ufsm.br/educacaoespecial/article/view/19833 
A partir dessa "garimpada" dos descritores nos repositórios já citados, nas pesquisas referendadas neste estado do conhecimento e nas Revistas de Educação Especial da UFSM, foi possível constatar lacunas importantes a serem pesquisadas devido à pouca e/ou inexistência de publicações científicas no contexto de formação permanente de professores para a docência inclusiva, inclusive, na EBTT, conforme proposta na investigação.

Neste levantamento, evidenciam-se estudos referentes à inclusão nos Institutos Federais em diferentes objetivos, evidenciando a carência de investigações que contemplem a temática proposta, principalmente, na Educação Profissional. Não foram encontradas pesquisas referentes a este tema específico, o que legitima a abertura de um novo habitus bourdieuno.

Portanto, a temática apresentada neste estudo aponta a relevância e a necessidade da continuidade de pesquisas futuras. Devido a falta de orientação, de regulação, de resolução referentes à formação para a Educação Especial na política da educação inclusiva, vem ferindo a compreensão, pois sugere de forma implícita, uma substituição da área de Educação Especial para um conjunto de serviços, de recursos e de técnicas descritas ao docente de AEE, possibilitando risco de perdermos às especificidades inerentes à educação para a pessoa com deficiência. Nesse sentido, acreditamos ser necessários maiores aprofundamentos em estudos futuros.

\section{Referências}

Antunes. H, S. (2001). Ser aluna, ser professora: uma aproximação das significações sociais instituídas e instituintes construídas ao longo dos ciclos de vida pessoal e profissional. Tese.

Antunes, H, S. (2005). Imaginário social e Formação inicial de professores: tecendo relações entre teorias e práticas educativas. In: Trajetória docente: o encontro da teoria com a prática. Antunes, H. S. (org). Ed. Pallotti, 19-32.

Bardin, L. (1979). Análise de conteúdo. Ed.70.

Beyer, H, O. (2005). Inclusão e avaliação na escola: de alunos com necessidades educacionais especiais. Mediação.

Bogdan, R. \& Biklen, S. (1994). Investigação qualitativa em educação. Porto Editora.

Bourdieu, P. (2011). O Poder Simbólico. (15a ed.), Bertrand Brasil.

Charlot, B. (2000). Da relação com o saber: elementos para uma teoria. Artes Médicas Sul.

Carvalho, L, C. \& Antunes, H, S. (2015). Metanoia - Histórias de vida e formação continuada em uma escola do campo. Pacto Editorial.

Cunha, M, I, da. (1989). O bom professor e sua prática. Campinas, SP: Papirus. (22a ed.), Coleção Magistério: Formação e Trabalho Pedagógico.

Fernandes, C, M, B. (1999). Sala de aula universitária - ruptura, memória educativa, territorialidade - desafio da construção pedagógica do conhecimento. Tese, Porto Alegre.

Gil, A. C. (2002). Como elaborar projetos de pesquisa. (4a ed.), Atlas.

Hermann, N. (2002). Hermenêutica e Educação [o que você precisa saber sobre...]. DP\&A.

Imbernón, F. (2009). Formação permanente do professorado: novas tendências. Cortez.

Januzzi, G, S, de M. (2012). A educação do deficiente no Brasil: dos primórdios ao início do século XXI. Campinas, SP: Autores Associados.

LARROSA, J. B (2002). Notas sobre a experiência e o saber de experiência. Revista Brasileira de Educação, 19, $20-28$.

Mazzotta, M, J, S. (1996). Educação Especial no Brasil: história e políticas públicas. Cortez.

Morosini, M, C. (2015). Estado de conhecimento: sua contribuição à ruptura de pré-conceitos. Revista de Educação da UFSM. (40).

Morosini, M, C. \& Fernandes, C, M, B. (2014). Educação Por Escrito, Porto Alegre, (5), (2), 154-164.

Nóvoa. A. (1992). Os professores e a sua formaçãoPublicações Dom Quixote.

Passeggi, M, da C. Abrahão, M, H, M, B. \& Delory-Momberger, C. (2012). Reabrir o passado, inventar o devir: a inenarrável condição biográfica do ser. In: Passeggi, M. da C.; Abraahão, M. H. M. B. (Orgs.). Dimensões epistemológicas e metodológicas da pesquisa (auto)biográfica: Tomo II. Porto Alegre: EDIPUCRS; Natal: EDUFRN; Salvador: EDUNEB, p. 29-57.

Sassaki, R. (1999). Inclusão: construindo uma sociedade para todos. (3a ed.), WVA. 